(c) American Dairy Science Association, 2006.

\title{
High-Intensity Pulsed Electric Field Variables Affecting Staphylococcus aureus Inoculated in Milk
}

\author{
Á. Sobrino-López, R. Raybaudi-Massilia, and O. Martín-Belloso ${ }^{1}$ \\ Department of Food Technology, University of Lleida, 25198 Lleida, Spain
}

\begin{abstract}
Staphylococcus aureus is an important milk-related pathogen that is inactivated by high-intensity pulsed electric fields (HIPEF). In this study, inactivation of Staph. aureus suspended in milk by HIPEF was studied using a response surface methodology, in which electric field intensity, pulse number, pulse width, pulse polarity, and the fat content of milk were the controlled variables. It was found that the fat content of milk did not significantly affect the microbial inactivation of Staph. aureus. A maximum value of $4.5 \mathrm{log}$ reductions was obtained by applying 150 bipolar pulses of $8 \mu \mathrm{s}$ each at $35 \mathrm{kV} / \mathrm{cm}$. Bipolar pulses were more effective than those applied in the monopolar mode. An increase in electric field intensity, pulse number, or pulse width resulted in a drop in the survival fraction of Staph. aureus. Pulse widths close to $6.7 \mu \mathrm{s}$ lead to greater microbial death with a minimum number of applied pulses. At a constant treatment time, a greater number of shorter pulses achieved better inactivation than those treatments performed at a lower number of longer pulses. The combined action of pulse number and electric field intensity followed a similar pattern, indicating that the same fraction of microbial death can be reached with different combinations of the variables. The behavior and relationship among the electrical variables suggest that the energy input of HIPEF processing might be optimized without decreasing the microbial death.

Key words: high-intensity pulsed electric field, response surface methodology, Staphylococcus aureus, milk
\end{abstract}

\section{INTRODUCTION}

The percentage of people suffering from foodborne diseases each year has been reported to be up to $30 \%$. Unlike traditional outbreaks, current bursts of foodborne diseases often spread over a wide geographic area involving a potentially high number of patients (Ro-

Received March 27, 2006.

Accepted April 26, 2006.

${ }^{1}$ Corresponding author: omartin@tecal.udl.es court et al., 2003). In the United States, for instance, around 76 million cases of foodborne diseases, resulting in 325,000 hospitalizations and 5,000 deaths, are estimated to occur each year (WHO, 2002). Among the identified microorganisms causing outbreaks and illnesses, Staphylococcus aureus is one of the main foodborne pathogens (Buzby and Roberts, 1997). Staphylococcus aureus represented the largest number of infections (66\%) among annual foodborne outbreaks of infectious intestinal disease in England and Wales from 1992 to 1993 (Cowden et al., 1995).

Staphylococcal food poisoning is a typical intoxication resulting from the ingestion of food containing one or more preformed staphylococcal enterotoxins. Symptoms usually develop rapidly, usually 1 to $6 \mathrm{~h}$ after ingestion, are of relatively short duration, and have no lasting effects. Because of the mild symptoms and rapid recovery, a doctor is seldom consulted and many cases are not reported. Although Staph. aureus is a poor competitor and is often overgrown by other microorganisms, milk has been implicated in outbreaks of staphylococcal infection. One of the largest outbreaks ever recorded occurred in June-July 2000 in the Kansai District in Japan. There were 13,420 victims although the primary vehicle was reconstituted milk from powdered skim milk. An enterotoxin-producing strain of Staph. aureus was the etiologic agent. Symptoms appeared in $83.4 \%$ of interviewed victims within $6 \mathrm{~h}$, with 3 to $4 \mathrm{~h}$ being the peak period (Jay et al., 2005). Up to 1,000 foodborne outbreaks are registered every year in Spain, $8 \%$ of which are related to dairy products, of which Staph. aureus comprises almost 6\% (Hernández-Pezzi et al., 2004).

Because milk is one of the most important foods in human nutrition susceptible to both spoilage and pathogenic microorganisms, pasteurization is mandatory. However, preformed enterotoxins are not destroyed even though pasteurization is capable of destroying the microorganism (ICMSF, 1998). One outbreak occurred in Kentucky in 1985 in which 860 schoolchildren became ill after drinking $2 \%$ chocolate milk. The milk was inadvertently kept for several hours at room temperature before pasteurization. No staphylococci were isolated, but staphylococcal enterotoxin A was detected in the pasteurized milk (Everson et al., 1988). 
Furthermore, thermal pasteurization causes undesirable changes in the organoleptic qualities, nutritional, or technological properties of milk. Generation of a "cooked" flavor is the most obvious sensory change in milk processed by heat (Wirjantoro and Lewis, 1997), whereas degradation of its nutritional value, such as protein denaturation and the loss of vitamins, are only detected with analytical procedures.

The increasing demand for fresh-like quality products has promoted the effort for developing innovative nonthermal food preservation methods. Among them, high-intensity pulsed electric field (HIPEF) processing is a nonthermal treatment that offers the advantage of inactivating microorganisms with minimal impact on quality and nutritional factors (Sampedro et al., 2005). Inactivation of different pathogens, such as Escherichia coli (Martín et al., 1997; Evrendilek and Zhang, 2005), Salmonella Dublin (Sensoy et al., 1997), or Staph. aureus (Sobrino-López and Martín-Belloso, 2006), by applying a HIPEF treatment in milk has been demonstrated by several authors. However, most of the studies using HIPEF have been performed in model solutions (Bendicho et al., 2002) so that their results exclude the influence of the food's composition on microbial resistance. For instance, HIPEF research on milk has been developed in milk ultrafiltrate despite milk being a complex food in which proteins and fat are present. Martín et al. (1997) found that inactivation of $E$. coli in milk was more limited than in a buffer solution, because of the presence of milk proteins. Furthermore, there is no agreement on the possible influence of fat content on HIPEF inactivation. Moreover, the only process parameters considered in those studies were field strength and treatment time, even though the relationships among the different process parameters acting simultaneously may be important in optimizing the inactivation of microorganisms by HIPEF.

The purpose of this research was to study the individual or combined effect of Staph. aureus inactivation in milk due to HIPEF, in which the controlled variables were electric field intensity, pulse number, pulse width, pulse polarity, and fat content of milk.

\section{MATERIALS AND METHODS}

\section{Staphylococcus aureus Culture}

Staphylococcus aureus CECT 240 (Department of Food Technology, University of Lleida, Spain) was used as a target microorganism and maintained on slants of plate count agar (Biokar Diagnostics, Beauvais, France) at $4^{\circ} \mathrm{C}$ throughout the experiments. Staphylococcus aureus cells were grown by inoculation and incubation in tryptone soy broth up to approximately $10^{9}$ $\mathrm{cfu} / \mathrm{mL}$ with orbital agitation at $200 \mathrm{rpm}$ at $35^{\circ} \mathrm{C}$ for $6 \mathrm{~h}$.
Table 1. Electrical conductivity of milk at $25^{\circ} \mathrm{C}$

\begin{tabular}{ll}
\hline Fat content & $\begin{array}{l}\text { Electrical } \\
\text { conductivity } \\
(\mathrm{mS} / \mathrm{cm})\end{array}$ \\
\hline Whole milk & $5.50 \pm 0.01$ \\
1.5\% fat milk & $5.85 \pm 0.01$ \\
Skim milk & $6.03 \pm 0.01$ \\
\hline
\end{tabular}

${ }^{1}$ Mean $\pm \mathrm{SE}$ of 3 measurements.

\section{Treatment Media}

Homogenized UHT milk was supplied by a dairy plant and stored at $4^{\circ} \mathrm{C}$ (Granja Castelló, Mollerussa, Lleida, Spain). The $\mathrm{pH}$ of the milk was $6.68 \pm 0.02$ at $25^{\circ} \mathrm{C}$ and a $\mathrm{pH}$ meter was used for the measurement (Crison 2001 pH-meter; Crison Instruments SA, Alella, Barcelona, Spain). The electrical conductivity of the milk was measured at $25^{\circ} \mathrm{C}$ and determined with a conductivity meter (Testo 240 conductivimeter; Testo $\mathrm{GmbH}$ and Co, Lenzkirch, Germany). Table 1 shows the electrical conductivity of the milk with different fat contents.

\section{Sample Preparation}

Before HIPEF treatment, samples of Staph. aureus were prepared by inoculating milk with cells of the microorganism suspended in tryptone soy broth at the midexponential phase to a final concentration of approximately $10^{7} \mathrm{cfu} / \mathrm{mL}$. Air bubbles of the sample were removed with a diaphragm vacuum pump (Vacuubrand, Wertheim, Germany).

\section{HIPEF Equipment}

A continuous-flow HIPEF system was used to carry out this study. The treatment device was an OSU-4F HIPEF unit (The Ohio State University, Columbus) that discharges square-shaped pulses within 8 cofield flow chambers. Gap distance and volume in each chamber were $0.29 \mathrm{~cm}$ and $0.012 \mathrm{~cm}^{3}$, respectively. The pulse frequency was set to $100 \mathrm{~Hz}$ and the treatment temperature was kept under $25^{\circ} \mathrm{C}$ using a cooled water bath to rule out thermal effects.

\section{Survival Fraction of Staphylococcus aureus}

The untreated and treated samples were serially diluted in peptone water, spread-plated on plate count agar plates, and incubated for $48 \mathrm{~h}$ at $30^{\circ} \mathrm{C}$. The number of viable cells of Staph. aureus after applying a HIPEF treatment was expressed as survival fraction, $s$, which was calculated as $\mathrm{N} / \mathrm{N}_{0}$, where $\mathrm{N}_{0}$ was the initial count in samples before the HIPEF treatment, and $\mathrm{N}$ was the 
Table 2. Central composite response surface design and microbial inactivation of Staphylococcus aureus suspended in milk and submitted to different combinations of fat content and high-intensity pulsed electric field (HIPEF) variables

\begin{tabular}{|c|c|c|c|c|c|c|c|}
\hline \multirow[b]{4}{*}{$\begin{array}{l}\text { Assay } \\
\text { no. }{ }^{1}\end{array}$} & \multirow[b]{4}{*}{$\begin{array}{l}\text { Point } \\
\text { type }\end{array}$} & \multicolumn{6}{|c|}{ Uncoded variables } \\
\hline & & \multirow{3}{*}{$\begin{array}{l}\text { Electric } \\
\text { field } \\
\text { intensity } \\
(\mathrm{kV} / \mathrm{cm})\end{array}$} & \multirow[b]{3}{*}{$\begin{array}{l}\text { Pulse } \\
\text { number }\end{array}$} & \multirow{3}{*}{$\begin{array}{l}\text { Pulse } \\
\text { width } \\
(\mu s)\end{array}$} & \multirow{3}{*}{$\begin{array}{l}\text { Fat } \\
\text { content } \\
(\%)\end{array}$} & \multicolumn{2}{|c|}{ Pulse type } \\
\hline & & & & & & Monopolar & Bipolar \\
\hline & & & & & & \multicolumn{2}{|c|}{$\begin{array}{c}\text { Response variable } \\
(-\log s)\end{array}$} \\
\hline 1 & Factorial & 35 & 150 & 8 & 0.0 & 3.55 & 4.48 \\
\hline 2 & Factorial & 35 & 150 & 4 & 0.0 & 2.43 & 3.48 \\
\hline 3 & Factorial & 35 & 50 & 8 & 3.0 & 1.38 & 2.70 \\
\hline 4 & Factorial & 25 & 150 & 4 & 3.0 & 0.40 & 0.96 \\
\hline 5 & Factorial & 35 & 50 & 4 & 3.0 & 1.83 & 1.92 \\
\hline 6 & Factorial & 25 & 50 & 8 & 0.0 & 0.22 & 0.58 \\
\hline 7 & Factorial & 25 & 150 & 8 & 3.0 & 1.39 & 1.52 \\
\hline 8 & Factorial & 25 & 50 & 4 & 0.0 & 0.00 & 0.17 \\
\hline 9 & Axial & 25 & 100 & 6 & 1.5 & 0.78 & 1.54 \\
\hline 10 & Axial & 35 & 100 & 6 & 1.5 & 3.36 & 3.90 \\
\hline 11 & Axial & 30 & 50 & 6 & 1.5 & 1.33 & 1.56 \\
\hline 12 & Axial & 30 & 150 & 6 & 1.5 & 2.36 & 2.34 \\
\hline 13 & Axial & 30 & 100 & 4 & 1.5 & 1.51 & 1.11 \\
\hline 14 & Axial & 30 & 100 & 8 & 1.5 & 2.33 & 2.23 \\
\hline 15 & Axial & 30 & 100 & 6 & 0.0 & 1.74 & 2.54 \\
\hline 16 & Axial & 30 & 100 & 6 & 3.0 & 2.10 & 2.86 \\
\hline 17 & Center & 30 & 100 & 6 & 1.5 & $1.14^{3}$ & $2.97^{3}$ \\
\hline
\end{tabular}

${ }^{1}$ Order of assays was randomized, and HIPEF treatment was set at $100 \mathrm{~Hz}$.

${ }^{2}$ Data shown are the mean of 2 treatment repetitions, each assay was performed in triplicate; $s=$ survival fraction.

${ }^{3}$ Data shown are the mean of 5 repetitions.

count after each treatment. Microbial inactivation was calculated as $-\log s$.

\section{Experimental Design}

A response surface analysis was used to evaluate the effect of the different variables of the HIPEF treatment on the survival fraction of Staph. aureus in milk. A face-centered, central composite design with 5 factors was the proposed experimental design (Myers and Montgomery, 2002). The independent variables were electric field intensity, pulse number, pulse width, pulse type, and fat content of milk, and were set at 25 or 35 $\mathrm{kV} / \mathrm{cm}, 50$ or 150 pulses, 4 or $8 \mu \mathrm{s}$, in the monopolar or bipolar mode, and with 0 or $3 \%$ fat, respectively. Variable levels were chosen according to previous studies. The experimental design along with each experimental condition is shown in Table 2. A duplicate was performed, resulting in 2 blocks of experiments. The order of assays within each block was randomized and performed in triplicate.

The effect of the 5 independent variables was modeled using a polynomial response surface. The second-order response function was predicted by the following equation:

$$
-\log s=\beta_{0}+\sum_{i=1}^{3} \beta_{i} X_{i}+\sum_{i=1}^{3} \beta_{i i} X_{i}^{2}+\sum_{i=1 j=i+1}^{2} \sum_{i j}^{3} \beta_{i} X_{j}
$$

where factor $X$ represents the encoded values of the variables, and $\beta$ terms are the constant coefficients. The nonsignificant terms $(P \geq 0.05)$ were deleted from the second-order polynomial model after an ANOVA, and a new ANOVA was performed to obtain the coefficients of the final equation for better accuracy.

To perform this study, Design Expert 6.0.1 software (Stat Ease Inc., Minneapolis, MN) was used in all analyses and generated plots. A 95\% confidence interval was used for all procedures.

\section{RESULTS AND DISCUSSION}

\section{Checking of the Fitted Model}

To determine the effect of HIPEF treatment on microbial death of Staph. aureus inoculated in milk, a response surface design was performed. The process variables were electric field intensity, pulse number, pulse width, pulse polarity, and the fat content of the milk. Table 2 shows the microbial inactivation of Staph. aureus achieved for each combination of the controlled variables. No microbial death of Staph. aureus inocu- 
Table 3. Analysis of variables for the response surface quadratic model of Staphylococcus aureus in milk

\begin{tabular}{lrrc}
\hline & Mean & & \\
Source $^{1}$ & square & $F$-value & $P>F$ \\
\hline Quadratic model $^{\prime}$ & 4.1260 & 21.1649 & $<0.0001^{\mathrm{a}}$ \\
$n$ & 12.2007 & 62.5855 & $<0.0001^{\mathrm{a}}$ \\
$\tau$ & 1.6259 & 8.3402 & $0.0056^{\mathrm{a}}$ \\
$F$ & 4.3068 & 22.0923 & $<0.0001^{\mathrm{a}}$ \\
$P p$ & 0.2331 & 1.1958 & 0.2790 \\
$E^{2}$ & 7.4844 & 38.3922 & $<0.0001^{\mathrm{a}}$ \\
$n^{2}$ & 0.3340 & 1.7131 & 0.1961 \\
$\tau^{2}$ & 1.0194 & 5.2290 & 0.0262 \\
$f^{2}$ & 1.8064 & 9.2663 & $0.0036^{\mathrm{a}}$ \\
$E \cdot n$ & 0.0847 & 0.4347 & 0.5125 \\
$E \cdot \tau$ & 0.7673 & 3.9362 & $0.0524^{\mathrm{a}}$ \\
$E \cdot f$ & 0.0091 & 0.0467 & 0.8297 \\
$E \cdot p p$ & 0.1194 & 0.6124 & 0.4373 \\
$n \cdot \tau$ & 0.3811 & 1.9548 & 0.1678 \\
$n \cdot f$ & 0.9167 & 4.7022 & $0.0345^{\mathrm{a}}$ \\
$n \cdot p p$ & 0.2626 & 1.3470 & 0.2509 \\
$\tau \cdot f$ & 0.0229 & 0.1176 & 0.7330 \\
$\tau \cdot p p$ & 0.0973 & 0.4989 & 0.4830 \\
$f \cdot p p$ & 0.1351 & 0.6931 & 0.4088 \\
Pure error & 0.0229 & 0.1175 & 0.7331 \\
SD & & 0.081 & \\
Mean & & 0.44 & \\
R-squared & & 1.92 & \\
Adjusted R-squared & & 0.88 & \\
\hline
\end{tabular}

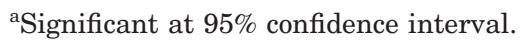

${ }^{1} E=$ Electric field intensity; $n=$ pulse number; $\tau=$ pulse width; $f=$ fat content of milk; $p p=$ pulse polarity.

lated in skim milk was observed with either monopolar or bipolar pulses when a HIPEF treatment at $25 \mathrm{kV} /$ $\mathrm{cm}$ electric field intensity and 50 pulses of $4 \mu \mathrm{s}$ pulse width were applied. Conversely, a HIPEF treatment at $35 \mathrm{kV} / \mathrm{cm}$ of electric field intensity and 150 pulses of 8 $\mu \mathrm{s}$ pulse width achieved $4.5 \mathrm{log}$ reductions of Staph. aureus in skim milk when bipolar pulses were used, and $3.6 \mathrm{log}$ units were registered in the case of monopolar pulses with the same variable combination.

Table 3 shows the ANOVA for the response surface model. The second-order response function showed a significant fit with the data $(P<0.0001)$ and the determination coefficient, $\mathrm{R}^{2}$, was 0.88 , meaning that the model was adequate for predicting the response across the design space. The variables electric field intensity, pulse number, and pulse width affected microbial inactivation linearly, whereas only the quadratic term of pulse width were significant. There were also differences in the survival fraction of Staph. aureus achieved by monopolar and bipolar pulses. The combined action of pulse number with electric field intensity and pulse width was included in the model as interaction terms. Coefficients of the fitted model are shown in Table 4. The fat content of the milk produced no statistical effect on the inactivation of Staph. aureus.

\section{Effect of Fat Content of Milk}

The fat content of the milk did not modify the resistance of Staph. aureus to a HIPEF treatment. However, the influence of this variable on the HIPEF inactivation of microorganisms is still unclear. Grahl and Markl (1996) indicated that the fat content of the medium is inversely related to microbial inactivation and claimed that fat particles of milk seemed to protect bacteria against electric pulses. Their results could be explained by variation of milk conductivity, because this variable decreases as the percentage of fat increases. However, as reflected in the statistical analysis (Table 3), the variation in fat content did not significantly modify the counts of Staph. aureus suspended in milk after applying a HIPEF treatment even though the electrical conductivity of whole and skim milk varied from 5.50 to $6.03 \mathrm{mS} / \mathrm{cm}$, respectively (Table 1). Coinciding with our results, some authors found no difference when comparing samples treated by HIPEF with a different fat content. Reina et al. (1998) inoculated Listeria monocytogenes in whole and skim milk samples, which were treated at $30 \mathrm{kV} / \mathrm{cm}$ for 100 to $600 \mu \mathrm{s}$, and no significant differences were found. Michalac et al. (2003) also reported that electrical conductivity showed no effect on the inactivation of different bacteria in the HIPEF-processed milk.

\section{Effect of Pulse Polarity}

Because pulse polarity is a categorical variable, the microbial inactivation of Staph. aureus suspended in milk due to a HIPEF treatment using monopolar pulses can be fitted through equation 2 , and in the case of bipolar pulses the survival fraction of Staph. aureus can be modeled by equation 3 :

$$
\begin{gathered}
-\log s=-7.607+0.144 \cdot E-0.020 \cdot n+1.337 \cdot \tau \\
-0.112 \cdot \tau^{2}+7.02 \cdot 10^{-4} \cdot E \cdot n+1.693 \cdot 10^{-3} \cdot n \cdot \tau
\end{gathered}
$$

and

$$
\begin{gathered}
-\log s=-6.971+0.144 \cdot E-0.020 \cdot n+1.337 \cdot \tau \\
-0.112 \cdot \tau^{2}+7.02 \cdot 10^{-4} \cdot E \cdot n+1.693 \cdot 10^{-3} \cdot n \cdot \tau
\end{gathered}
$$

where $s$ is the survival fraction, $E$ is the electric field intensity $(\mathrm{kV} / \mathrm{cm}), n$ the pulse number, and $\tau$ the pulse width $(\mu s)$.

Among HIPEF processing parameters, pulse polarity was one of the most important factors $(P<0.0001)$ in Staph. aureus inactivation (Table 3). In comparison with the monopolar mode, bipolar pulses enhanced HIPEF treatment. As the intercept terms of equation 1 
Table 4. Significant regression coefficients of the quadratic model for the survival fraction of Staphylococcus aureus suspended in milk

\begin{tabular}{|c|c|c|c|c|}
\hline Factor $^{1}$ & $\begin{array}{l}\text { Coefficient } \\
\text { estimate }^{2}\end{array}$ & Low & High & $\begin{array}{l}\text { Standard } \\
\text { error }\end{array}$ \\
\hline \multicolumn{5}{|l|}{ Intercept } \\
\hline Monopolar pulses & -7.607 & -10.524 & -3.980 & 1.636 \\
\hline Bipolar pulses & -6.971 & -10.304 & -3.560 & 1.686 \\
\hline$E$ & 0.144 & 0.110 & 0.178 & 0.017 \\
\hline$n$ & -0.020 & -0.045 & -0.0053 & 0.013 \\
\hline$\tau$ & 1.337 & 2.032 & 0.265 & 0.442 \\
\hline$\tau^{2}$ & -0.112 & -0.162 & -0.060 & 0.026 \\
\hline$E \cdot n$ & $7.02 \times 10^{-4}$ & $7.60 \times 10^{-5}$ & $1.32 \times 10^{-3}$ & $3.11 \times 10^{-4}$ \\
\hline$n \cdot \tau$ & $1.69 \times 10^{-3}$ & $1.30 \times 10^{-4}$ & $3.30 \times 10^{-3}$ & $7.93 \times 10^{-4}$ \\
\hline
\end{tabular}

${ }^{1} E=$ Electric field intensity; $n=$ pulse number; $\tau=$ pulse width.

${ }^{2} 95 \%$ confidence interval.

and 2 show, inactivation due to bipolar pulses remained within the defined space over microbial death due to monopolar pulses. A difference of over $0.64 \mathrm{log}$ units was observed between the mono- and bipolar modes when HIPEF treatment was set at 150 pulses of $8 \mu \mathrm{s}$ each and $35 \mathrm{kV} / \mathrm{cm}$ (Figure 1). It is generally assumed that microbial cells are affected by pulse polarity, even though there is a lack of information about the effect of this variable on the inactivation of several microorganisms in milk or in other complex media. However, it is believed that bipolar pulses cause stress and fatigue on the cell membrane and facilitate its electric breakdown due to alternating changes in the movement of charged molecules (Chang, 1989) and by reducing the deposition of solids on the electrode surface, which decreases food electrolysis (Qin et al., 1994). Evrendilek

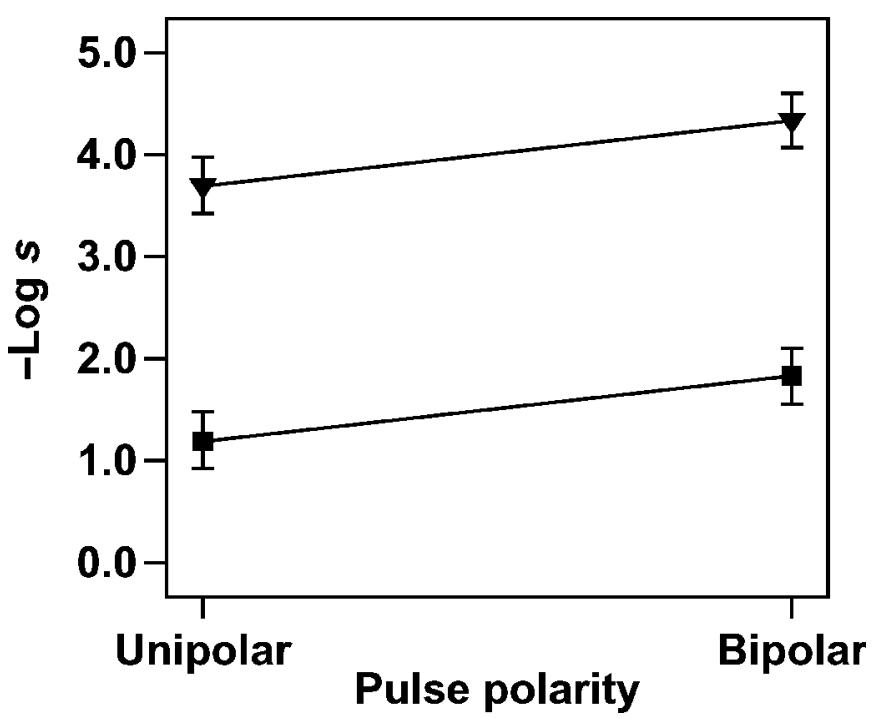

Figure 1. Effect of pulse polarity on the survival fraction $(s)$ of Staphylococcus aureus inoculated in milk when the high-intensity pulsed electric field (HIPEF) treatment was set at $25(\mathbf{\square})$ or $35(\boldsymbol{\nabla})$ $\mathrm{kV} / \mathrm{cm}$ electric field intensity of 150 pulses of $8 \mu \mathrm{s}$ each. and Zhang (2005) reported that bipolar pulses produced $1.88 \log$ units of inactivation of $E$. coli in skim milk whereas monopolar pulses only produced $1.27 \mathrm{log}$ units. However, they found no significant difference between the bipolar and monopolar mode for the inactivation of $E$. coli in apple juice in the same study. In contrast, Elez-Martínez et al. (2004) observed an extra 0.9 log reduction in the inactivation of Lactobacillus brevis in orange juice by the bipolar mode compared with the monopolar mode at $35 \mathrm{kV} / \mathrm{cm}$ and a treatment time of $1,000 \mu \mathrm{s}$.

\section{Effect of Electric Field Intensity}

As seen in Figure 2, the higher the electric field intensity, the greater the inactivation of the Staph. aureus

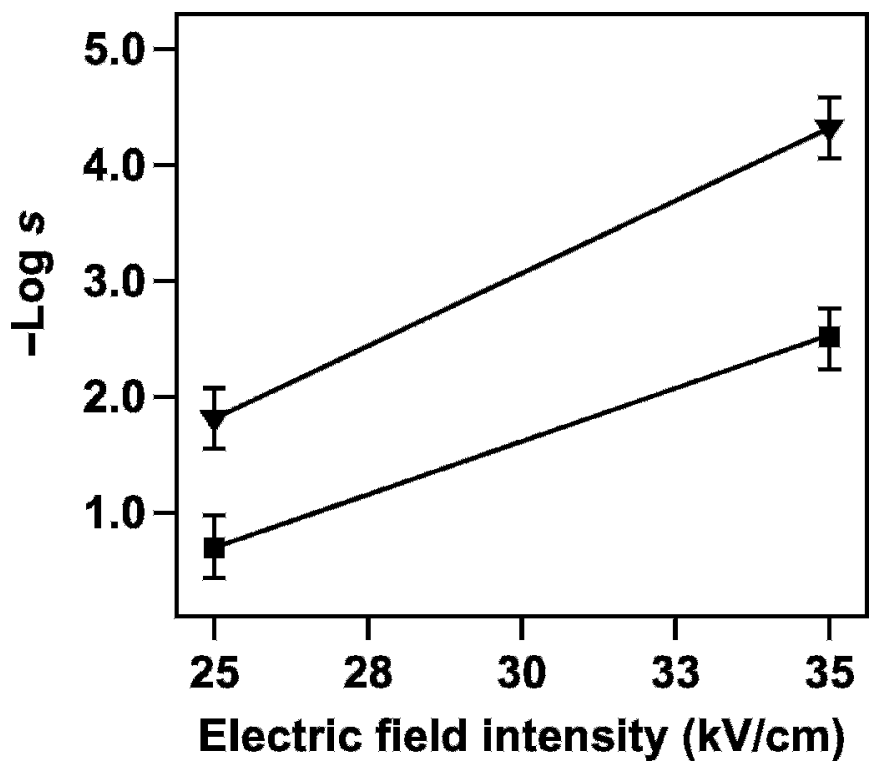

Figure 2. Effect of electric field intensity on survival rate $(s)$ of Staphylococcus aureus suspended in milk in bipolar mode, $8 \mu \mathrm{s}$ pulse width, and $50(\mathbf{\square})$ or $150(\boldsymbol{\nabla})$ pulse number. 
population achieved. Electric field intensity resulted in a marked effect on Staph. aureus $(P<0.0001)$, although the value of $35 \mathrm{kV} / \mathrm{cm}$ could not be exceeded without the electrical breakdown of milk in our experimental conditions. Other authors have reported electric field intensity as being one of the main parameters determining microbial destruction (Martín et al., 1997; Elez-Martínez et al., 2005). Cell death of Staph. aureus increased from 1.8 to $4.3 \mathrm{log}$ units when $E$ rose from 25 to $35 \mathrm{kV} / \mathrm{cm}$, respectively, with the other variables set at 150 pulses, $8 \mu$ s pulse width, and in the bipolar mode. Similar microbial reductions were obtained by other authors, such as Evrendilek et al. (2004), who found that a HIPEF treatment of $450 \mu \mathrm{s}$ treatment times at $35 \mathrm{kV} / \mathrm{cm}$ reduced the population of Staph. aureus suspended in skim milk by 3.7 log units. Raso et al. (1999) reported up to 4.0 log reductions when Staph. aureus suspended in milk was treated with 40 $\mathrm{kV}$ of input voltage and 40 pulses. However, no cell death was achieved at treatments below $25 \mathrm{kV} / \mathrm{cm}$ with 100 pulses of $4 \mu \mathrm{s}$. This result is consistent with those obtained by Evrendilek et al. (2004), who determined a critical or threshold value of electric field intensity of at least $20 \mathrm{kV} / \mathrm{cm}$ for Staph. aureus suspended in skim milk. In contrast, a critical electric field intensity of $11.7 \mathrm{kV} / \mathrm{cm}$ was reported by Damar et al. (2002) when the HIPEF treatment was carried out in peptone saline. The low value in their study can be explained by the protective properties of milk vs. peptone saline, because milk is a complex food material, whereas peptone saline is simply a dilute solution. Nevertheless, Staph. aureus appears to be more resistant than other bacteria to HIPEF treatment in milk. The Bacillus cereus population suspended in skim milk was reduced by more than 2 log units after a HIPEF treatment of $90 \mu \mathrm{s}$ at $35 \mathrm{kV} /$ cm (Michalac et al., 2003), whereas less than $1.8 \mathrm{log}$ reductions of Staph. aureus were achieved with the same treatment values. Escherichia coli was inactivated by $1.88 \log$ reductions in skim milk when submitted to a bipolar HIPEF treatment of $24 \mathrm{kV} / \mathrm{cm}$ and 141 $\mu \mathrm{s}$ (Evrendilek and Zhang, 2005), whereas no microbial destruction of Staph. aureus was observed with a HI$\mathrm{PEF}$ treatment with the same variables. In addition, the critical electric field intensity of $E$. coli inoculated in skim milk was close to $14 \mathrm{kV} / \mathrm{cm}$, and the minimal pulse number ranged from 1.9 to 5.4 pulses, which corresponded to a treatment time of 4.8 and $9.7 \mu \mathrm{s}$, respectively (Martín et al., 1997).

\section{Effect of Pulse Number}

The coefficient of the variable pulse number, $n$, was negative, meaning that the counts of Staph. aureus should decrease linearly with $n$ (equations 2 and 3 ).

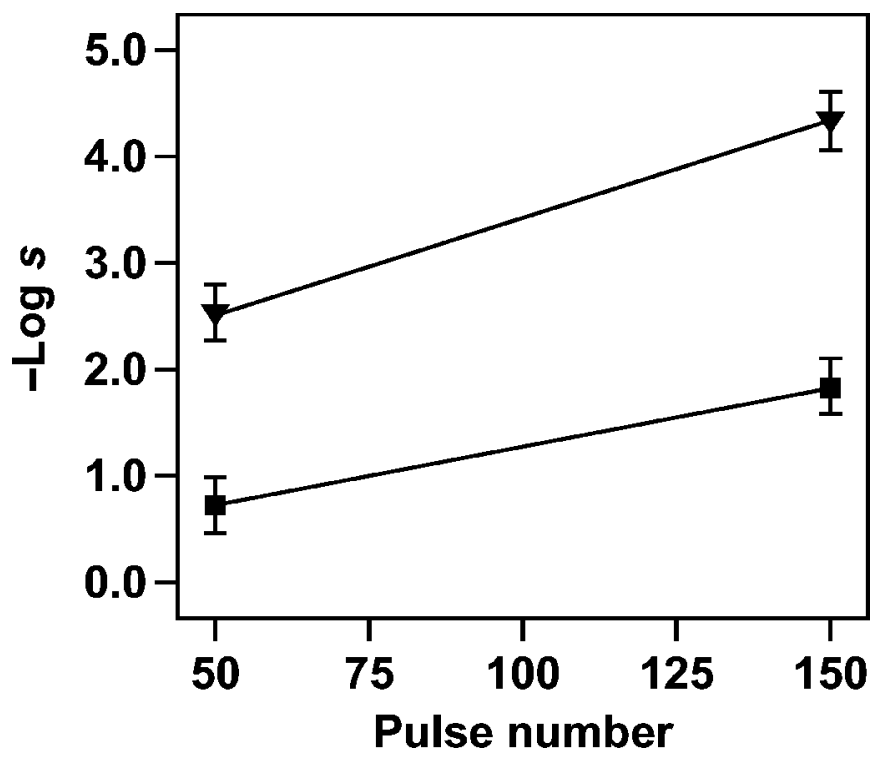

Figure 3. Effect of pulse number on survival rate (s) of Staphylococcus aureus suspended in milk when high-intensity pulsed electric field (HIPEF) treatment was set in bipolar mode, $8 \mu$ s pulse width, and $25(\mathbf{\square})$ or $35(\boldsymbol{\nabla}) \mathrm{kV} / \mathrm{cm}$ electric field intensity.

However, the expected behavior of $n$ was apparently not clearly expressed according to equation 2 and 3 , as is reflected in Figure 3 . At $35 \mathrm{kV} / \mathrm{cm}$ and $8 \mu \mathrm{s}$ pulse width, only $2.5 \log$ reductions were registered with 50 pulses, whereas $4.3 \mathrm{log}$ units were obtained with 150 pulses. Hence, the single negative effect of $n$ may be masked by the positive effect in either of the interactions, $E \cdot n$ or $n \cdot \tau$ (equations 2 and 3 ). Therefore, these results agree with those generally accepted, whereby the microbial population decreases as the pulse number rises. The survival fraction of Staph. aureus suspended in milk ultrafiltrate was reduced by more than $2 \mathrm{log}$ units when applying a HIPEF treatment of 50 pulses at $16 \mathrm{kV} / \mathrm{cm}$ (Pothakamury et al., 1995). In similar conditions, only a $0.5 \mathrm{log}$ reduction was observed when 60 pulses at $20 \mathrm{KV} / \mathrm{cm}$ were applied to samples of Staph. aureus inoculated in peptone saline (Damar et al., 2002). As for other microorganisms, samples of milk were treated with 30 pulses at $25 \mathrm{kV} / \mathrm{cm}$ and up to 2.0 $\log$ reductions in the $E$. coli population were obtained (Martín et al., 1997). The lethal effect of increasing the pulse number has been related to the resulting decrease in the critical potential difference of the cell membrane (Barbosa-Canovas et al., 1999).

\section{Effect of Pulse Width}

The inactivation of Staph. aureus depended on the negative quadratic term of pulse width, $\tau$ (equations 2 and 3). Hence, an increment in the value of $\tau$, with other 
variables constant, resulted in lower increments in the microbial inactivation of this microorganism. The number of log reductions increased from 3.3 to 4.3 log units when pulse width increased from 4 to $8 \mu \mathrm{s}$, applying 150 bipolar pulses at $35 \mathrm{kV} / \mathrm{cm}$ (Figure 4). However, the maximal destruction of Staph. aureus under these conditions was reached at approximately $7.1 \mu \mathrm{s}$ pulse width; the survival fraction decreased slightly from 7.1 to $8.0 \mu \mathrm{s}$. Under a HIPEF treatment of 50 bipolar pulses at $35 \mathrm{kV} / \mathrm{cm}$, the maximum was observed at $6.3 \mu \mathrm{s}$ pulse width (Figure 4). This phenomenon has received little attention because traditional research has been performed with, at most, 2 values of pulse width. Martín et al. (1997) noted that the application of 25 pulses of $0.7 \mu \mathrm{s}$ each at $25 \mathrm{kV} / \mathrm{cm}$ reduced the survival fraction of $E$. coli inoculated in skim milk by less than $1 \mathrm{log}$ cycle, but that under the same conditions and with a $1.8-\mu$ s pulse width, a reduction of more than 2 log cycles was achieved. These authors explained that the increase in the microbial death depended on the higher energy applied in each pulse, despite the fact that no wider pulses were considered.

\section{Effect of the Combined Action of Pulse Number and Pulse Width}

Pulse width and pulse number exert a reciprocal influence, as revealed by the significance of the interaction term, $n \cdot \tau$ (Table 3 ). The product of these 2 variables defines the discrete variable treatment time, $t$ ( $\mu \mathrm{s}$; equation 4). Treatment time is also considered to be one of the main variables affecting cell inactivation (ElezMartínez et al., 2005) because the longer the electric field intensity is applied, the more damage to the membrane is found. Different authors agree that the inactivation of different microorganisms was greater when the treatment time increased (Martín et al., 1997; ElezMartínez et al., 2005). An increase from 2.2 to $4.3 \mathrm{log}$ reductions was observed between samples treated for $200 \mu \mathrm{s}$ (50 pulses of $4 \mu \mathrm{s}$ pulse width) and 1,200 $\mu \mathrm{S}$ (150 pulses of $8 \mu \mathrm{s}$ ), respectively, when electric field intensity was $35 \mathrm{kV} / \mathrm{cm}$ and bipolar pulses were used (Figure 5). Compared with the electrical conditions set in this study, Evrendilek et al. (2004) determined that skim milk inoculated with Staph. aureus and subjected to HIPEF for $450 \mu \mathrm{s}$ at $35 \mathrm{kV} / \mathrm{cm}$ resulted in a significant decrease of a $3 \mathrm{log}$ reduction. Raso et al. (1999) observed that Staph. aureus and CNS spp. in milk could be inactivated over 4 and $2 \log$ cycles, respectively, after a HIPEF treatment of 40 pulses at $40 \mathrm{kV} / \mathrm{cm}$ :

$$
T=n \cdot \tau \text {. }
$$

As shown in Figure 5, the combined effect of the variables $n$ and $\tau$ followed a nonlinear curve with the
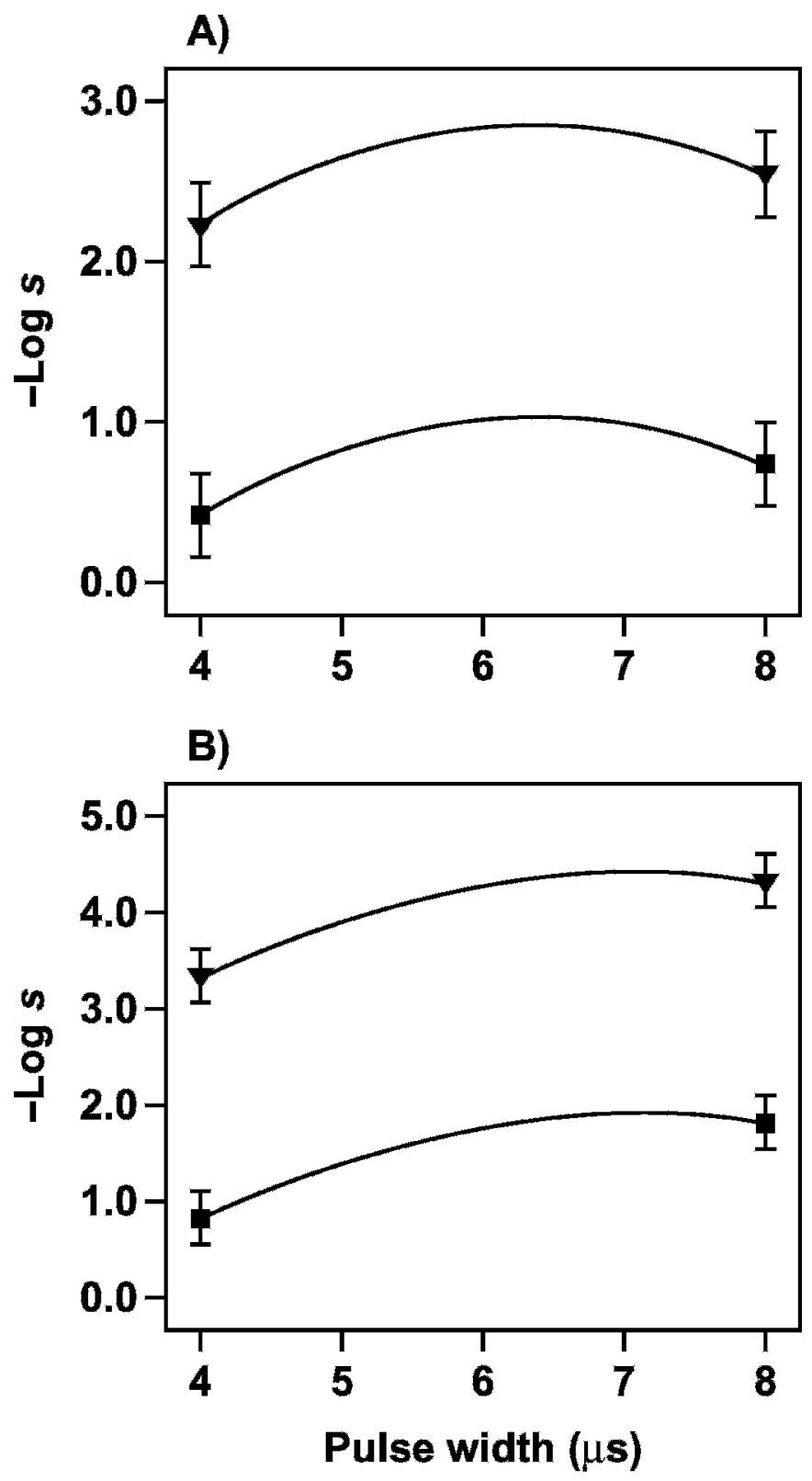

Figure 4. Effect of pulse width on survival rate (s) of Staphylococcus aureus inoculated in milk when high-intensity pulsed electric field (HIPEF) treatment was carried out in bipolar mode, and at $25(\boldsymbol{\square})$ or $35(\boldsymbol{\nabla}) \mathrm{kV} / \mathrm{cm}$ electric field intensity $(\mathrm{A}=50$ pulses; $\mathrm{B}=$ 150 pulses).

microbial destruction of Staph. aureus. Two different aspects affecting the survival fraction and the HIPEF process application were derived from the interaction $n \cdot \tau$. On one hand, it is possible to exchange different combinations of the variables $n$ and $\tau$ to achieve the same level of microbial inactivation. In this way, an inactivation of $4 \log$ reductions was observed with either 150 pulses of $5.2 \mu \mathrm{s}$ each, which resulted in a treatment time of $780 \mu \mathrm{s}$, or with 125 pulses of $6.8 \mu \mathrm{s}$ 

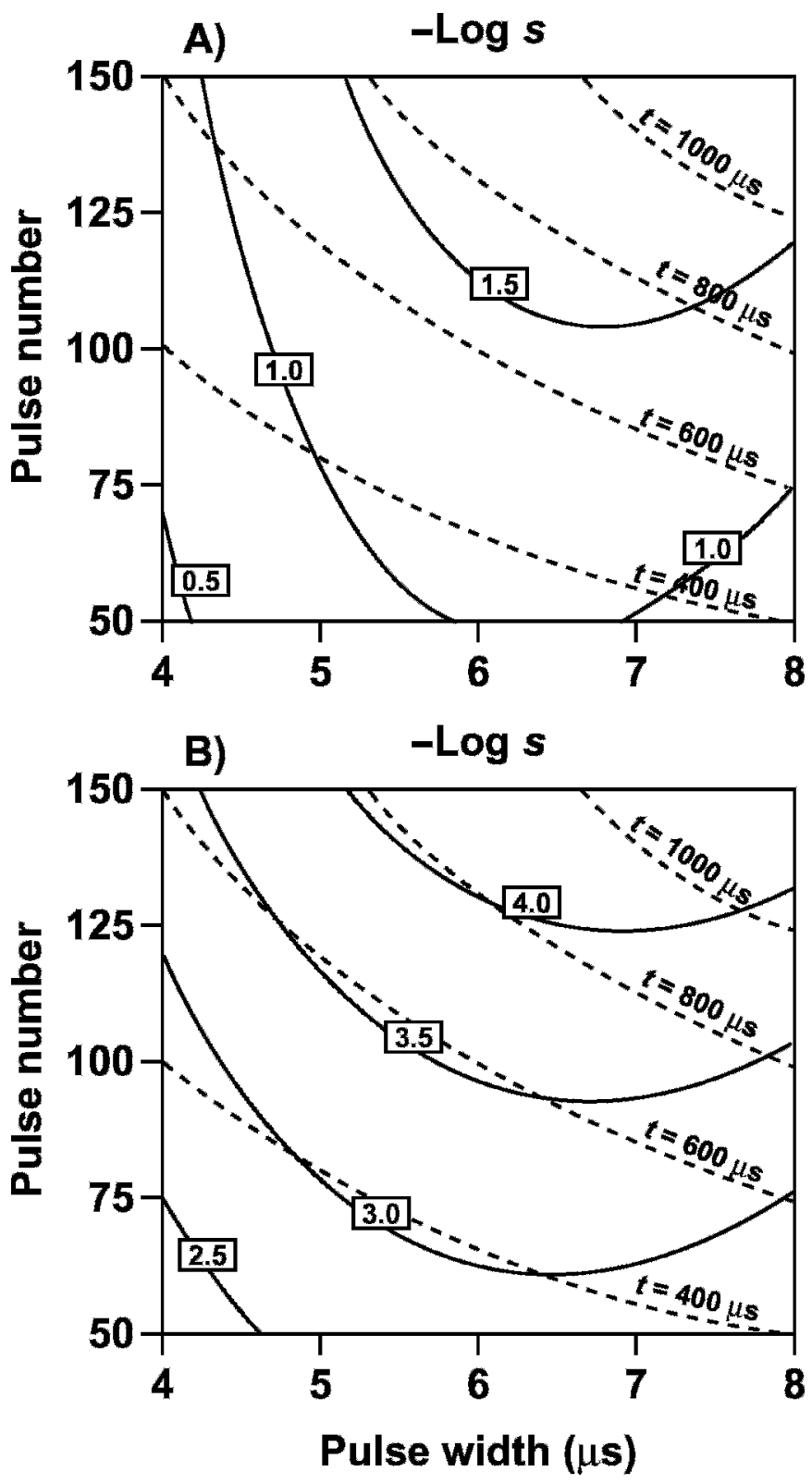

Figure 5. Effect of the combination of pulse number and pulse width in bipolar mode on survival rate (s) of Staphylococcus aureus ( $t=$ treatment time; $\mathrm{A}=25 \mathrm{kV} / \mathrm{cm} ; \mathrm{B}=35 \mathrm{kV} / \mathrm{cm}$ ).

each, resulting in an 850- $\mu$ s treatment time, when the HIPEF treatment was carried out in both cases at 35 $\mathrm{kV} / \mathrm{cm}$ and in bipolar mode (Figure 5). Moreover, energy input in each treatment chamber, $W(\mathrm{~J})$, can be calculated as:

$$
W=k_{1} \cdot k_{2} \cdot E \cdot I \cdot f \cdot t=k_{1} \cdot k_{2} \cdot E \cdot I \cdot f \cdot n \cdot \tau
$$

where $k_{1}$ is an HIPEF device constant, $k_{2}$ is a processing constant, $E$ is the electric field intensity in $\mathrm{kV} / \mathrm{cm}, I$ is the current in $\mathrm{A}, f$ is the frequency in $\mathrm{Hz}$, and $t$ is the treatment time in $\mu$ s (Evrendilek et al., 2004). Thus, the combination of a greater number of shorter pulses (150 pulses of $5.2 \mu \mathrm{s}$ each) reduced the energy input in comparison with the treatment of 125 pulses of $6.8 \mu \mathrm{s}$ each. Consequently, it could be feasible to minimize the energy requirements of the HIPEF treatment by selecting the lowest treatment time while maintaining the process objective of inactivation. Furthermore, as is shown in Figure 5, the use of a greater number of shorter pulses resulted in greater microbial death than a treatment performed with a smaller number of longer pulses when the treatment time was equal. Considering a treatment time of $600 \mu \mathrm{s}$, a treatment of 150 pulses of $4 \mu \mathrm{s}$ pulse width reduced the population of Staph. aureus by $3.3 \mathrm{log}$ units, whereas a treatment of 75 pulses of $8 \mu \mathrm{s}$ each only achieved $2.9 \log$ reductions (Figure 5).

On the other hand, every curve from the contour plot shows a minimum on the survival fraction of Staph. aureus (Figure 5). If the microbial death was kept at $4.0 \mathrm{log}$ reductions, for instance, the combination of 125 pulses of $6.8 \mu \mathrm{s}$ width at $35 \mathrm{kV} / \mathrm{cm}$ led to a minimum at this level of destruction, whereas the minimum at $3.0 \mathrm{log}$ units corresponded to the combination of 60 pulses of $6.5 \mu \mathrm{s}$ each. Pulse width and pulse number of each minimum decreased as microbial inactivation dropped, even though pulse width seemed to be included in a narrow range of values. Pulse width of the optimized points followed the equation:

$$
\tau=7.56 \cdot 10^{-3} \cdot \mathrm{n}+5.97,
$$

which can be obtained by the derivation of equation 1 or 2 , and varied from 6.4 to $7.0 \mu \mathrm{s}$ when the pulse number was 50 and 150, respectively. Therefore, pulse widths close to $6.7 \mu \mathrm{s}$ were shown to be more effective on microbial inactivation of Staph. aureus independently of the pulse number and electric field intensity applied.

The effect of combining pulse width and pulse number on microbial death has not been clearly explained owing to the contradictory results obtained by different authors. Elez-Martínez et al. (2005) reported that shorter pulses might be considered more effective in destroying Lactobacillus brevis in orange juice. On the other hand, Abram et al. (2003) observed that longer pulse widths resulted in higher inactivation of Lactobacillus plantarum suspended in a buffer solution than shorter pulse widths at constant treatment time and electric field intensity. The HIPEF equipment, the flow mode of processing, process conditions, microorganism resistance, or sample media could explain the lack of agreement of the results achieved in different studies. 


\section{Effect of the Combined Action of Pulse Number and Electric Field Intensity}

The survival fraction of Staph. aureus was affected by the combined effect of electric field intensity and pulse number, which was included in the response model as the interaction $E \cdot n$ (equations 2 and 3 ). The positive value of its coefficient suggests that higher inactivation can be achieved by an increase in any or both variables. Considering bipolar pulses of $8 \mu$ s pulse width, the survival fraction decreased from 0.7 to 4.3 $\log$ units when $E$ and $n$ changed from $25 \mathrm{kV} / \mathrm{cm}$ and 50 pulses to $35 \mathrm{kV} / \mathrm{cm}$ and 150 pulses, respectively (Figure 6). Therefore, the simultaneous increase in the 2 variables resulted in an increment of microbial inactivation of $3.6 \mathrm{log}$ units, whereas the sum of single increments in each variable while the other one was kept constant was only $2.7 \mathrm{log}$ reductions. Electric field intensity and pulse number, expressed as the treatment time, have been signaled as the major factors determining microbial inactivation in HIPEF processing (Martín et al., 1997; Elez-Martínez et al., 2005). Reina et al. (1998) found that at short treatment times $(100 \mu \mathrm{s})$, there was no difference between 25 or $35 \mathrm{kV} / \mathrm{cm}$ of electric field intensity, but that at 300 and $600 \mu$ s treatment times, a higher electric field intensity resulted in a greater reduction in viable cells. However, the effect of both variables acting simultaneously have yet been clearly elucidated, although BarbosaCanovas et al. (1999) concluded that as the pulse number increased, the critical potential difference of the cell membrane decreased, resulting in a higher susceptibility of microorganisms to HIPEF.

Moreover, $E \cdot n$ interaction allows different $(E, n)$ coordinates with the same inactivation level to be exchanged. As observed in Figure 6, a bipolar HIPEF treatment of $8 \mu \mathrm{s}$ pulse width at $35 \mathrm{kV} / \mathrm{cm}$ and 80 pulses was equivalent to a treatment at $30 \mathrm{kV} / \mathrm{cm}$ and 150 pulses, while microbial inactivation was held at $3.0 \mathrm{log}$ units. Therefore, the interaction $E \cdot n$ suggests that the same damage value in the cell membrane could occur after carrying out different combinations of the treatment variables. Because the temperature increment in a cofield flow treatment chamber depends on the pulse number and the quadratic term of electric field intensity (Evrendilek et al., 2004), the nonthermal character of the treatment is also inferred from the decreasing electric field intensity despite the increase in the value of pulse number.

\section{CONCLUSIONS}

Staphylococcus aureus was efficiently inactivated in milk by HIPEF treatment, although this microorganism seemed to be resistant. A maximum inactivation

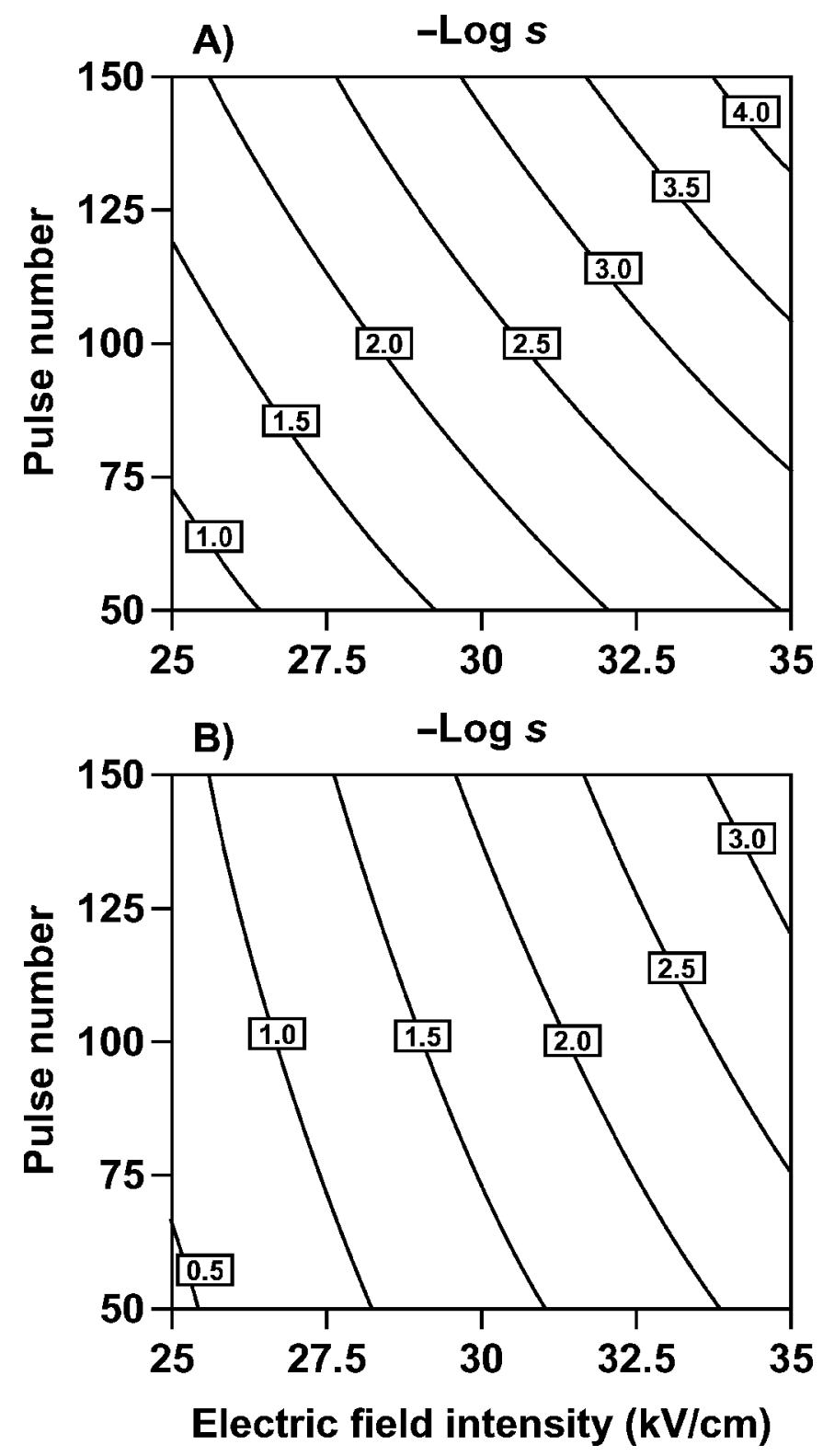

Figure 6. Effect of the combined action of electric field intensity and pulse number on survival rate (s) of Staphylococcus aureus (polarity = bipolar; $\mathrm{A}=8 \mu \mathrm{s} ; \mathrm{B}=4 \mu \mathrm{s})$.

of 4.5 log units was observed when HIPEF treatment was carried out at 150 bipolar pulses of $8 \mu \mathrm{s}$ each at $35 \mathrm{kV} / \mathrm{cm}$. Among the studied variables, polarity, pulse number, pulse width, electric field intensity, and the combined action of pulse number with pulse width or electric field intensity significantly affected the microbial death of Staph. aureus, which could be modeled by a second-order equation. The fat content of milk did not modify microbial inactivation.

An incremental increase on pulse number, pulse width, or electric field intensity resulted in higher mi- 
crobial inactivation, although the effect of pulse width on microbial inactivation was nonlinear. The use of bipolar pulses raised the survival fraction less within the defined ranges of the variables than that obtained by applying the HIPEF treatment in the monopolar mode. The combined action of pulse number and pulse width revealed that pulses within 6.3 to $7.1 \mu$ s showed higher microbial inactivation with a lower number of applied pulses. Furthermore, a HIPEF treatment of a greater number of narrow pulses resulted in a greater microbial death than a HIPEF treatment with a lower number of wide pulses for an equal value of treatment time. Different combinations of pulse number and electric field intensity also achieved equivalent microbial inactivation. The response of the electrical variables suggested that it is possible to optimize the HIPEF treatment by reducing the amount of energy input and, consequently, the temperature increase during the process while microbial inactivation is kept constant. Consequently, the death of Staph. aureus in milk was solely due to cell damage caused by the application of electric fields and not to a possible temperature increment. Variables affecting the HIPEF process showed that microbial inactivation was not only led by the single variables but also by their combination. Hence, further research is needed to clearly define the variables affecting the process and the mechanisms involved in cell death.

\section{REFERENCES}

Abram, F., J. P. P. M. Smelt, R. Bos, and P. C. Wouters. 2003. Modeling and optimization of inactivation of Lactobacillus plantarum by pulsed electric field treatment. J. Appl. Microbiol. 94:571-579.

Barbosa-Canovas, G. V., M. M. Gonogora-Nieto, U. R. Pothakamury, and B. G. Swanson. 1999. Preservation of foods with pulses electric fields. Academic Press, London, UK.

Bendicho, S., G. V. Barbosa-Canovas, and O. Martín. 2002. Milk processing by high intensity pulsed electric fields. Trends Food Sci. Technol. 13:195-204.

Buzby, J. C., and T. Roberts. 1997. Economic costs and trade impacts of microbial foodborne illness. World Health Stat. Q. 50:57-66.

Chang, D. C. 1989. Cell poration and cell fusion using an oscillating electric field. Biophys. J. 56:641-652.

Cowden, J. M., P. G. Wall, G. Adak, H. Evans, S. Le Baigue, and D. Ross. 1995. Outbreaks of foodborne infectious intestinal disease in England and Wales: 1992-1993. Commun. Dis. Rep. Rev. 5:109-126.

Damar, S., F. Bozoglu, M. Hizal, and A. Bayindirli. 2002. Inactivation and injury of Escherichia coli O157:H7 and Staphylococcus aureus by pulsed electric fields. World J. Microbiol. Biotech. 18:1-6.

Elez-Martínez, P., J. Escolà-Hernández, R. C. Soliva-Fortuny, and O. Martín-Belloso. 2004. Inactivation of Saccharomyces cerevisiae suspended in orange juice using high-intensity pulsed electric fields. J. Food Prot. 67:2596-2602.

Elez-Martínez, P., J. Escolà-Hernández, R. C. Soliva-Fortuny, and O. Martín-Belloso. 2005. Inactivation of Lactobacillus brevis in orange juice by high-intensity pulsed electric fields. Food Microbiol. 22:311-319.
Everson, M. L., M. W. Hinds, R. S. Bernstein, and M. S. Bergdoll. 1988. Estimation of human dose of staphylococcal enterotoxin A from a large outbreak of staphylococcal food poisoning involving chocolate milk. Int. J. Food Microbiol. 7:311-317.

Evrendilek, G. A., Q. H. Zhang, and E. R. Richter. 2004. Inactivation of Staphylococcus aureus in skim milk by pulsed electric treatment. Bioprocess Biosyst. Eng. 87:137-144.

Evrendilek, G. A., and Q. H. Zhang. 2005. Effects of pulse polarity and pulse delaying time on pulsed electric fields-induced pasteurization of $E$. coli O157:H7. J. Food Eng. 68:271-276.

Grahl, T., and H. Markl. 1996. Killing of micro-organisms by pulsed electric fields. Appl. Microbiol. Biotechnol. 45:148-157.

Hernández-Pezzi, G., A. Torres, P. Ordóñez, and C. Cevallos. 2004. Brotes de enfermedades transmitidas por alimentos. España, 1993-2002 (excluye brotes hídricos). Ministerio de Sanidad y Consumo, Instituto de Salud Carlos III, Boletín Epidemiológico 12:289-296.

International Commission of Microbiological Specifications in Food (ICMSF). 1998. Milk and dairy products. Pages 231-248 in Microorganisms in Foods 6, Microbial Ecology of Food Commodities. Blackie Academic \& Professional, London, UK.

Jay, J. M., M. J. Loessner, and D. A. Golden. 2005. Staphylococcal gastroenteritis. Pages 545-566 in Modern Food Microbiology. J. M. Jay, M. J. Loessner, and D. A. Golden, ed. Springer, New York, NY.

Mabrook, M. F., and M. C. Pretty. 2003. Effect of composition on the electrical conductance of milk. J. Food Eng. 60:321-325.

Martín, O., B. L. Quin, F. J. Chang, G. V. Barbosa-Canovas, and B. G. Swanson. 1997. Inactivation of Escherichia coli in skim milk by high intensity pulsed electric fields. J. Food Proc. Eng. 20:317-336.

Michalac, S., V. Alvarez, T. Ji, and Q. H. Zhang. 2003. Inactivation of selected microorganisms and properties of pulsed electric field processed milk. J. Food Process Preserv. 27:137-151.

Myers, R. H., and D. C. Montgomery. 2002. Response surface methodology: Process and product optimization using designed experiments. John Wiley \& Sons, New York, NY.

Pothakamury, U. R., A. Monsalve-González, G. V. Barbosa-Cánovas, and B. G. Swanson. 1995. Inactivation of Escherichia coli and Staphylococcus aureus in model foods by pulsed electric field technology. Food Res. Int. 28:167-171.

Qin, B. L., Q. H. Zhang, B. G. Swanson, and P. D. Pedrow. 1994. Inactivation of microorganisms by different pulsed electric fields of different voltage waveforms. IEEE Trans. Indust. App. 1:1047-1057.

Raso, J., M. Góngora, M. L. Calderón, G. V. Barbosa-Cánovas, and B. G. Swanson. 1999. Resistant microorganisms to high intensity pulsed electric field pasteurization of raw skim milk. Book of Abstracts: 59D-20, IFT Annual Meeting, Institute of Food Technologists, Chicago, IL.

Reina, L. D., Z. T. Jin, Q. H. Zhang, and A. E. Yousef. 1998. Inactivation of Listeria monocytogenes in milk by pulsed electric field. J. Food Prot. 61:1203-1206.

Rocourt, J., G. Moy, K. Vierk, and J. Schlundt. 2003. The present state of foodborne disease in OECD countries. World Health Organization (WHO), Geneva, Switzerland.

Sampedro, F., A. Rodrigo, A. Martínez, and D. Rodrigo. 2005. Quality and safety aspects of PEF application in milk and milk products. Crit. Rev. Food Sci. Nutr. 45:25-47.

Sensoy, I., Q. H. Zhang, and S. K. Sastry. 1997. Inactivation kinetics of Salmonella Dublin by pulsed electric field. J. Food Proc. Eng. $20: 367-381$

Sobrino-López, A., and O. Martín-Belloso. 2006. Enhancing inactivation of Staphylococcus aureus in skim milk by combining high intensity pulsed electric fields and nisin. J. Food Prot. 69:345-353.

World Health Organization (WHO). 2002. Food safety and foodborne illness. Fact sheet no. 237. WHO, Geneva, Switzerland.

Wirjantoro, T. I., and M. J. Lewis. 1997. Effect of nisin and high temperature pasteurization of shelf life of whole milk. J. Soc. Dairy Technol. 49:99-102. 